\title{
Three-Dimensional Numerical Study of Conjugate Heat Transfer in Diverging Microchannel
}

\author{
V S DURYODHAN ${ }^{1}$, ABHIMANYU SINGH $^{1}$, S G SINGH ${ }^{2}$ and AMIT AGRAWAL ${ }^{1, *}$ \\ ${ }^{1}$ Indian Institute of Technology Bombay, Powai, Mumbai 400 076, India \\ ${ }^{2}$ Indian Institute of Technology Hyderabad, Hyderabad 502 205, India
}

(Received on 28 April 2016; Accepted on 03 May 2016)

\begin{abstract}
Increase in applications of varying cross sectional area microchannels in microdevices has provided the need to understand fluid flow and heat transfer through such flow passages. This study focuses on conjugate heat transfer study through a diverging microchannel. Three-dimensional numerical simulations are performed using commercially available package. Diverging microchannels with different geometrical configurations (i.e. varying angle: $1-8^{\circ}$, depth: $86-200 \mu \mathrm{m}$, solid-tofluid thickness ratio: $1.5-4)$ are employed for this purpose. Simulations are carried out for varying mass flow rate $(3.3 \mathrm{x}$ $\left.10^{-5}-8.3 \times 10^{-5} \mathrm{~kg} / \mathrm{s}\right)$ and heat flux $\left(2.4-9.6 \mathrm{~W} / \mathrm{cm}^{2}\right)$ conditions. Heat distribution along the flow direction is studied to understand the effect of wall conduction. Wall conduction number $(M)$ varies from 0.006 to 0.024 for the range of parameters selected in the study. Wall conduction is observed to be a direct function of depth and solid-to-fluid thickness ratio, and varies inversely with angle of diverging microchannel. It is observed that the area variation and wall conduction contribute separately towards redistribution of the supplied heat flux. This leads to reduced temperature gradients in diverging microchannel. The results presented in this work will be useful for designing future microdevices involving heating or cooling.
\end{abstract}

Keywords: Wall Conduction; Diverging Microchannel; Heat Flux Gradient

\section{Introduction}

Study of heat transfer in varying cross section microchannels is relevant to micro-mixers, design of micro-devices for separating proteins, reducing boiling flow instability, besides being of fundamental interest. Yong and Teo (2014) based on their numerical study noted the increase in mixing and thus heat transfer rate with the use of converging-diverging microchannel. Fu and Pan (2010) showed that the diverging microchannel gives enhanced chemical reaction because of better diffusion mixing. Kates and Ren (2006) used a diverging microchannel for isoelectric focusing application using a temperature dependent $\mathrm{pH}$ gradient in a diverging microchannel. Hsieh et al. (2013) used a heated converging-diverging microchannel to stretch DNA molecules using thermoelectrophoresis and convection. Some efforts have also been made to reduce flow boiling instabilities by employing a diverging microchannel (Agrawal et al., 2012; Lee and Pan, 2008). Xuan et al. (2005) employed converging-diverging microchannel for particle separation using electrophoretic separation technique. Recently, Duryodhan et al. (2016) showed a way for achieving constant wall temperature using diverging microchannel. These applications exhibit the importance of heating in varying cross section microchannels.

However, the wall conduction effect through solid substrate starts dominating at microscale because of the large thermal conductivity ratio and thickness ratio of substrate to fluid in microchannels. As per Maranzana et al. (2004) wall conduction (defined later through Eq. 9) dominates if $M>0.01$. Study of wall conduction in uniform cross section microchannel report the distortion of supplied boundary condition. Limited studies on conjugate heat transfer in uniform

*Authorfor Correspondence: E-mail: aagrawal.iitb@gmail.com, Tel.: +91222576 7516 
cross section microchannel are available (Moharana et al., 2011; Celata et al., 2006; Fedorov and Viskanta, 2000). However, study of conjugate heat transfer in non-uniform/varying cross section microchannel has not received any attention. In the case of diverging microchannel, the surface area, perimeter, and aspect ratio (and hence the heat flux on the inner wall) varies in the flow direction; which makes the problem nontrivial. This wall conduction leads to substantial redistribution of the heat flux which could be of much importance for design optimization of the above mentioned microdevices. Obtaining a better understanding of these issues provided the motivation for undertaking this work.

The objective of the present work is to understand the effect of wall conduction on heat distribution in diverging microchannel. Numerical simulations of liquid flow through heated diverging microchannels are performed. Diverging microchannels with different geometrical configuration: angle $\left(\theta=1-8^{\circ}\right)$, depth $(\mathrm{H}$ $=86-200 \mu \mathrm{m})$, and solid-to-fluid thickness ratio $\left(\mathrm{t}_{\mathrm{s}} / \mathrm{t}_{\mathrm{f}}=\right.$ 1.5-4.0) have been employed for this purpose. Simulations have been carried out for the range of mass flow rate $\left(\dot{m}=3.3 \times 10^{-5}-8.3 \times 10^{-5} \mathrm{~kg} / \mathrm{s}\right)$ and heat flux $\left(q^{\prime \prime}=2.4-9.8 \mathrm{~W} / \mathrm{cm}^{2}\right)$ conditions. Heat distributions for all the simulated cases are discussed. Difference between two approaches (i.e. heat flux distribution versus heat distribution) employed for analyzing the conjugate effect has been explained.

\section{Numerical Methodology}

Three-dimensional numerical simulations of diverging microchannels with different geometrical configurations are undertaken in this study. Geometrical parameters of the microchannels considered are shown in Table 1. Inlet width (200 $\mu \mathrm{m})$, length $(20 \mathrm{~mm})$ and thermal conductivity $\left(\mathrm{k}_{\mathrm{s}}=\right.$ $148 \mathrm{~W} / \mathrm{m}-\mathrm{K})$ of all the microchannels are kept constant. All the microchannels are generated in Gambit software. Both solid and fluid zones are created and meshed using quadratic-hexahedral cells. Fig. 1 shows the three-dimensional model of diverging microchannel employed in the simulation; along with the geometrical configurations and boundary conditions.

Mass flow rate is specified at the inlet of microchannel whereas outlet is kept at constant
Table 1: Geometrical specifications of different cases used in the simulations

\begin{tabular}{|c|c|c|}
\hline \multicolumn{3}{|c|}{ Parameters } \\
\hline $\begin{array}{l}\text { Full angle, } \\
\qquad \theta\left(^{\circ}\right)\end{array}$ & $\begin{array}{l}\text { Depth, H } \\
\quad(\mu \mathrm{m})\end{array}$ & $\begin{array}{c}\text { Solid-to-fluid } \\
\text { thickness ratio }\left(\mathrm{t}_{\mathrm{s}} / \mathrm{t}_{\mathrm{f}}\right)\end{array}$ \\
\hline 1 & 86 & 2.32 \\
\hline 4 & 86 & 2.32 \\
\hline 8 & 86 & 2.32 \\
\hline 8 & 120 & 2.32 \\
\hline 8 & 200 & 2.32 \\
\hline 8 & 86 & 1.5 \\
\hline 8 & 86 & 4 \\
\hline
\end{tabular}

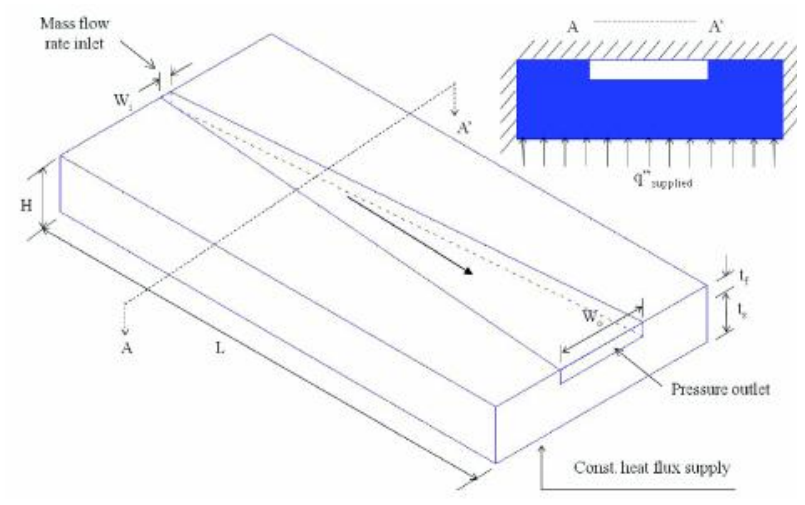

Fig. 1: Model of test section employed in numerical simulation showing geometrical parameters

atmospheric pressure. All the faces are specified with wall boundary conditions. No-slip boundary condition is specified at all the inner walls of microchannel (fluid zone). The outer bottom wall of the solid zone is maintained at constant heat flux condition whereas all other outer walls are thermally insulated.

Steady state three-dimensional version of conservation of mass, momentum, and energy equations (Eqs. 1-4) along with appropriate boundary conditions are solved using commercially available software Fluent.

Equation for conservation of mass

$$
\nabla \cdot(\rho \vec{V})=0
$$

Equation for conservation of momentum

$$
\vec{V} \cdot \nabla(\rho \vec{V})=-\nabla p+\nabla \cdot(\mu \nabla \vec{V})
$$


Equation for conservation of energy for fluid zone

$$
\vec{V} \cdot \nabla\left(\rho c_{p} T_{f}\right)=\nabla \cdot\left(k_{f} \nabla T_{f}\right)
$$

Equation for conservation of energy for solid zone

$$
\nabla \cdot\left(k_{s} \nabla T_{s}\right)=0
$$

where, $\vec{V}$ is the three-dimensional velocity vector, $T_{f}$ and $T_{s}$ are the temperatures of fluid and solid domain respectively, and $\mathrm{p}$ is the fluid pressure. Variation of fluid properties such as viscosity $(\mu)$ and thermal conductivity $\left(k_{f}\right)$ of the fluid with temperature are considered in the simulation as represented by Eq. 5 and 6.

$$
\begin{aligned}
\mu(T)= & \mu\left(T_{r e f}\right)\left(T / T_{r e f}\right)^{8.9} \\
& \times \exp \left[4700\left(1 / T-1 / T_{r e f}\right)\right] \\
k_{f}(T)= & (3.3+1.9 T) \times 10^{-3}
\end{aligned}
$$

The values of reference temperature and viscosity employed in Eq. 5 are $300 \mathrm{~K}$ and $8.55 \times 10^{-4}$ $\mathrm{kg} / \mathrm{m}$-s. However, density $(\rho)$ and specific heat capacity $\left(c_{p}\right)$ of fluid are assumed constant. Thermal conductivity of solid domain is denoted by $k_{s}$.

Second order discretization scheme is used for pressure equations; whereas the momentum and energy equations are discretized using the QUICK (Quadratic Upstream Interpolation for Convection Kinematic) scheme. A pressure based solver is selected to solve the flow equations using the SIMPLE (Semi-Implicit Method for Pressure Linked Equations) algorithm. The absolute convergence criterion for residuals of continuity and momentum equations is set at $10^{-6}$, whereas it is set at $10^{-9}$ for energy equation. A grid independence study is also performed and accordingly 0.45 and 1.3 million cells are selected for the fluid and solid zones respectively. Details about the grid independence study can be found in our earlier study (Duryodhan et al., 2015). Numerical results are first validated with the experimentally measured data for $8^{\circ}$ diverging microchannel. Figure 2 shows that the numerically obtained surface temperature variation is in good agreement (maximum 4\%) with the experimental data.

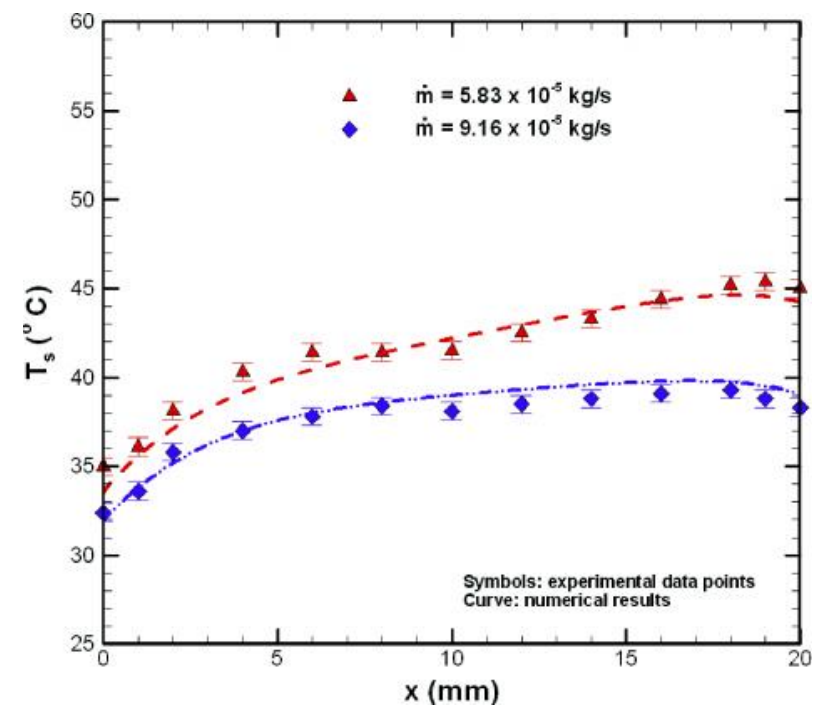

Fig. 2: Validation of surface temperature variation along the flow direction obtained numerically with that of experimental data points at two mass flow rates for $8^{\circ}$ diverging microchannel

Once the solution is converged, post-processing of the data is carried out to analyse the variation of surface temperature, fluid temperature, heat flux and Nusselt number along the flow direction. The objective of this paper is to study the heat distribution in diverging microchannel under the influence of wall conduction. In the previous work (Moharana et al., 2011; Celata et al., 2006; Fedorov and Viskanta, 2000), researchers studied the wall conduction in uniform cross sectional microchannel by analysing the deviation in heat flux distribution along flow direction from the supplied uniform heat flux condition. In the present work heat flux varies, firstly because of varying cross sectional area along the flow direction and secondly due to the wall conduction effect. The focus of this paper is to understand the effect of wall conduction on heat distribution. Therefore, we need to transform the heat flux into a quantity, which would be independent of effect of variation in cross sectional area. We propose to employ heat per unit length obtained by multiplying heat flux with perimeter as shown in Eq. 7.

$$
\begin{aligned}
& \text { Heat per unit length, } \\
& q^{\prime}(x)=q^{\prime \prime}(x) \times p(x)
\end{aligned}
$$

where, $q^{\prime \prime}(x)$ and $p(x)$ are respectively the local heat flux and perimeter. Note that the local heat flux is the 
area weighted average value calculated using the heat flux value at the bottom and side walls. However, perimeter is calculated as the sum of the bottom width and twice the height of the side wall. Variation of heat per unit length, obtained using Eq. 7, is plotted along the flow direction and discussed in the next section for the various cases studied here (Table 1). Variation in heat distribution is further analysed quantitatively by calculating its percentage standard deviation with respect to average value using Eq. 8.

Std. deviation in $q^{\prime}(\%)$

$$
=\frac{\sqrt{\frac{1}{N} \sum_{x=1}^{N}\left(q_{a v g}^{\prime}-q_{x}^{\prime}\right)^{2}}}{q_{a v g}^{\prime}} \times 100
$$

Maranzana et al. (2004) defined a nondimensional number called wall conduction number (M) in order to evaluate the strength of wall conduction. It is defined as the ratio of heat conduction through solid in the direction opposite to fluid flow to the heat transfer by fluid convection. In the present study wall conduction number is calculated for all the cases using Eq. 9.

$$
\begin{aligned}
& \text { Wall conduction number }(M) \\
& =\frac{k_{s} \times A_{s} \times\left(T_{s o}-T_{s i}\right)}{\dot{m} \times C_{p} \times\left(T_{f o}-T_{f i}\right) \times L}
\end{aligned}
$$

where, $A_{s}, T_{s o}$ and $T_{s i}$ are respectively the cross sectional area, and inlet-outlet temperatures of the solid. $T_{f o}$ and $T_{f i}$ are respectively the inlet and outlet fluid temperature span across microchannel length $L$. Wall conduction becomes important when wall conduction number is greater than 0.01 (Morini and Yang, 2013).

\section{Results}

Simulations for all the cases shown in Table 1 are performed for the range of mass flow rates $(\dot{m}=$ $\left.3.3-8.3 \times 10^{-5} \mathrm{~kg} / \mathrm{s}\right)$ and heat flux $\left(q^{\prime \prime}=2.4-9.8 \mathrm{~W} /\right.$ $\mathrm{cm}^{2}$ ) conditions. Heat distribution along the flow direction are plotted and discussed for all the cases. Heat distribution at the inner walls of diverging microchannels is discussed to understand the influence of depth, angle and solid-to-fluid thickness ratio on wall conduction.

\section{Effect of Microchannel Angle}

Three microchannels with varying angles of 1, 4 and $8^{\circ}$ are studied keeping all other geometrical parameters such as depth, length, inlet width, solidto-fluid thickness ratio same. Simulations are performed at constant supplied mass flow rate and heat flux of $5 \times 10^{-5} \mathrm{~kg} / \mathrm{s}$ and $4.8 \mathrm{~W} / \mathrm{cm}^{2}$ respectively. In case of $1^{\circ}$ diverging microchannel, heat per unit length continuously drops from the inlet to outlet albeit at non-uniform rate (Fig. 3). With the increase in divergence angle to $8^{\circ}$, heat distribution first drops suddenly at the entry of diverging microchannel. The dip in the heat distribution can be understood through the velocity profile shown in the inset of Fig. 3. The inset shows the point of zero or insignificant wall shear stress. The stagnant fluid zone near the wall leads to local heating and therefore drops in the heat absorbed. This is unlike the uniform cross sectional or $1^{\circ}$ diverging microchannel where one can expect the finite or significant wall shear stress. Further, heat dissipation increases till $5 \mathrm{~mm}$ beyond which it remains constant up to $15 \mathrm{~mm}$. After this point, heat drops with higher rate compared to that in lower angle diverging microchannel.

Further, it is observed that for diverging microchannel the percentage of standard deviation of heat distribution is larger in $1^{\circ}(26 \%$ with respect to the average value) compared to that in $4^{\circ}(19 \%)$

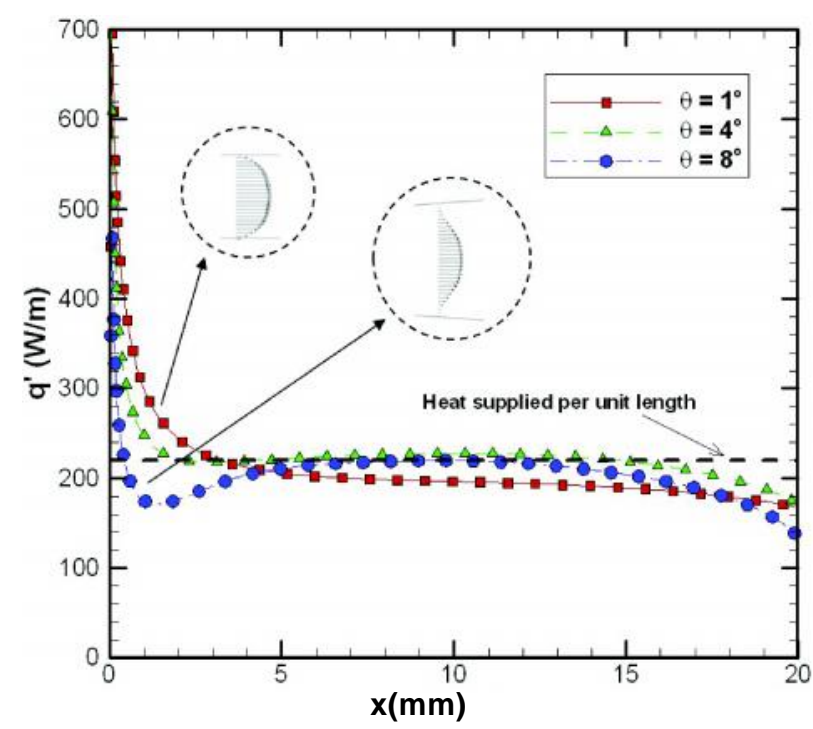

Fig. 3: Effect of angle on distribution of heat per unit length along the flow direction in diverging microchannel 
and $8^{\circ}(13 \%)$; see Fig. 3. This indicates that the wall conduction is larger in diverging microchannel having smaller angle. This is because the surface temperature gradient is larger in smaller angle diverging microchannel compared to that in larger angle microchannel as studied separately in Duryodhan et al. (2016).

\section{Effect of Microchannel Depth}

Three microchannels with $8^{\circ}$ angle of divergence but varying depths of 86,120 and $200 \mu \mathrm{m}$ are studied keeping all other geometrical parameters same. Simulations are performed at constant supplied mass flow rate and heat flux of $5 \times 10^{-5} \mathrm{~kg} / \mathrm{s}$ and $4.8 \mathrm{~W} /$ $\mathrm{cm}^{2}$ respectively. Fig. 4 shows the heat distribution per unit length in diverging microchannels having different depths. It is observed that heat distribution in diverging microchannel increases with the depth. The percentage variation in heat distribution increase from 13 to $21 \%$ for the increase in depth from 86 to $200 \mu \mathrm{m}$. However, qualitatively redistribution is observed to be more for diverging microchannel with depth 86 and $120 \mu \mathrm{m}$ (see Fig. 4). This is because of the two reason. First, for a given mass flow rate increase in depth leads to decrease in Reynolds number which reduces the convective heat transfer through the fluid. Second, the wall thickness for microchannel with larger depth is larger in order to keep constant solid-to-fluid thickness ratio. Both these factors increase the wall conduction leading to

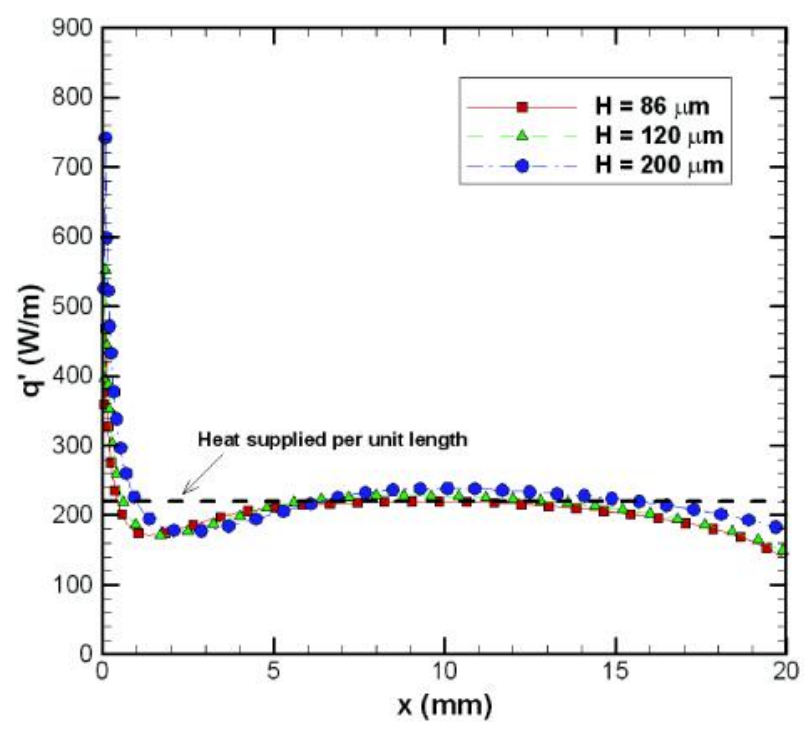

Fig. 4: Effect of depth on distribution of heat per unit length along the flow direction in diverging microchannel increase in percentage deviation of heat distribution with the increase in depth. Also, it is observed that the dip in heat variation near the inlet remains unaffected with the increase in depth.

\section{Effect of Solid-To-Fluid Thickness Ratio}

Three microchannels with same angle $\left(8^{\circ}\right)$, length (20 $\mathrm{mm})$ and depth $(86 \mu \mathrm{m})$ but varying solid-to-fluid thickness ratio $\left(\mathrm{t}_{\mathrm{s}} / \mathrm{t}_{\mathrm{f}}=1.5-4\right)$ are employed here. Simulations are performed at constant supplied mass flow rate and heat flux of $5 \times 10^{-5} \mathrm{~kg} / \mathrm{s}$ and $4.8 \mathrm{~W} /$ $\mathrm{cm}^{2}$ respectively. Figure 5 shows the heat distribution along the flow direction inside the diverging microchannels with varying solid-to-fluid thickness ratio. It shows that the standard deviation of heat distribution is $16 \%$ for $\mathrm{t}_{\mathrm{s}} / \mathrm{t}_{\mathrm{f}}=4$ whereas it is $12 \%$ and $13 \%$ respectively for $t_{s} / t_{f}$ of 2.32 and 1.5 . Therefore, the percentage deviation in heat distribution varies directly with the solid-to-fluid thickness ratio. This is because of the decrease in conduction resistance with increase in solid thickness, which facilitates additional wall heat conduction leading to increase in heat variation.

\section{Effect of Mass Flow Rate}

A microchannel with angle $8^{\circ}$, length $20 \mathrm{~mm}$, depth $86 \mu \mathrm{m}$ and solid-to-fluid thickness ratio $\left(\mathrm{t}_{\mathrm{s}} / \mathrm{t}_{\mathrm{f}}\right) 2.32$ is employed here. Simulations are performed at varying mass flow rate of $3.3 \times 10^{-5}-8.3 \times 10^{-5} \mathrm{~kg} / \mathrm{s}$ and

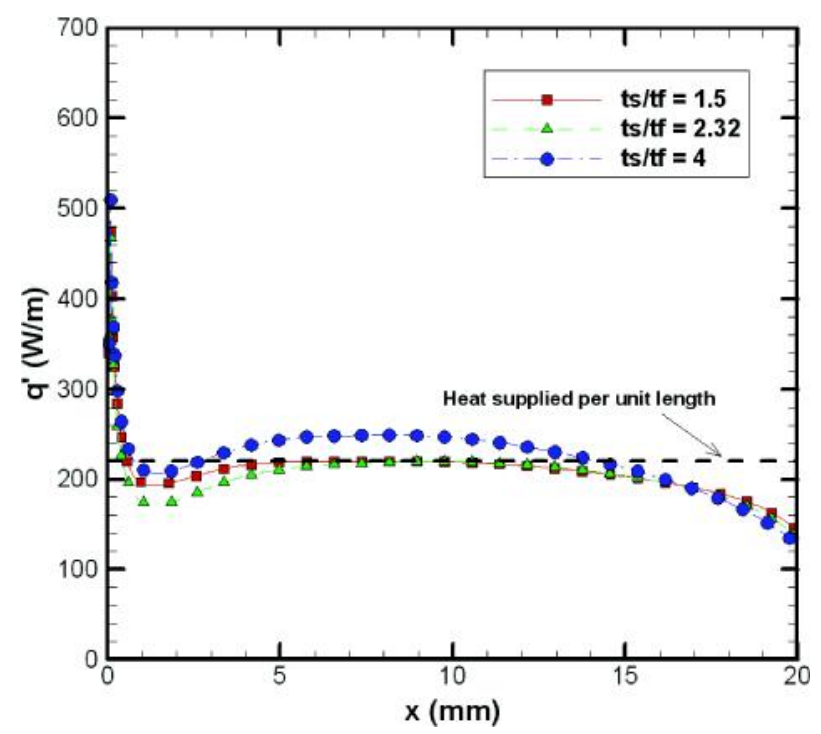

Fig. 5: Effect of solid-to-fluid thickness ratio on distribution of heat per unit length along the flow direction in diverging microchannel 


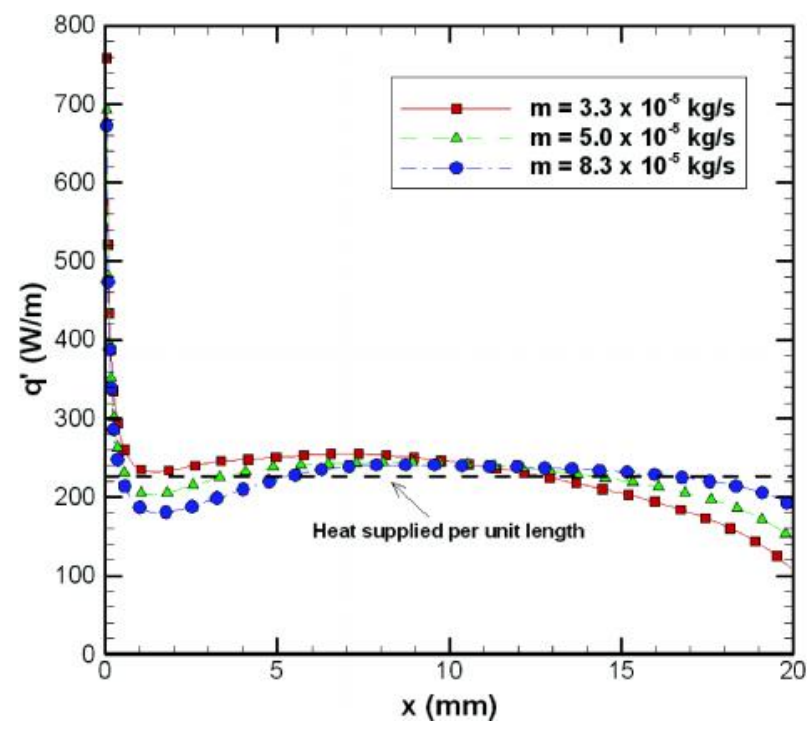

Fig. 6: Effect of mass flow rate on distribution of heat per unit length along the flow direction in diverging microchannel

supplied with constant heat flux of $4.8 \mathrm{~W} / \mathrm{cm}^{2}$. Figure 6 shows the heat distribution along the flow direction in diverging microchannel at varying flow rates. It is observed that the variation in heat distribution increases with the decrease in mass flow rate. For example, the percentage deviation of heat distribution in diverging microchannel varies from $14 \%$ to $21 \%$ for the decrease in mass flow rate from $8.3 \times 10^{-5} \mathrm{~kg} / \mathrm{s}$ to $3.3 \times 10^{-5} \mathrm{~kg} / \mathrm{s}$ (see Fig. 6). This is because of the fact that decrease in mass flow rates increases the temperature gradient at the surface leading to increase in wall conduction. In addition, the dip in the heat variation near inlet reduces with decrease in mass flow rates. This suggests that the stagnant fluid zone near the inlet of diverging microchannel is strongly dependant on the supplied mass flow rate.

\section{Effect of Heat Flux}

A microchannel with angle $8^{\circ}$, length $20 \mathrm{~mm}$, depth $86 \mu \mathrm{m}$ and solid-to-fluid thickness ratio $\left(\mathrm{t}_{\mathrm{s}} / \mathrm{t}_{\mathrm{f}}\right) 2.32$ is employed here. Simulations are performed in diverging microchannel supplied with constant mass flow rate of $5 \times 10^{-5} \mathrm{~kg} / \mathrm{s}$ and at different heat flux conditions of $2.4-9.6 \mathrm{~W} / \mathrm{cm}^{2}$. The variation in heat distribution is observed to be more at large supplied heat flux conditions (see Fig. 7). However, the percentage deviation in heat distribution remains invariant with the supplied heat flux conditions. For example, the percentage deviation in heat distribution remains close

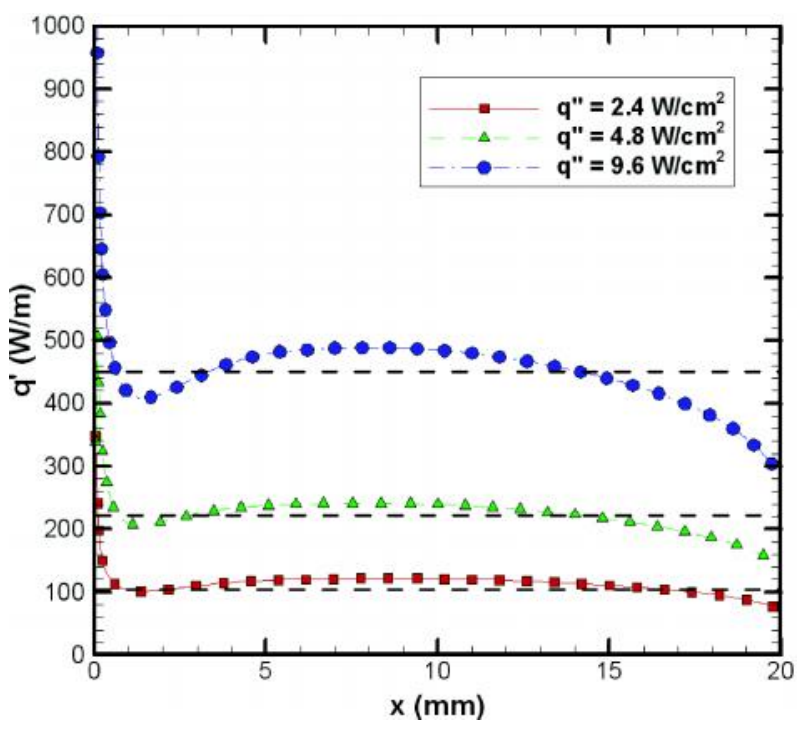

Fig. 7: Effect of supplied heat flux on distribution of heat per unit length along the flow direction in diverging microchannel

to $14 \%$ for diverging microchannel at all the supplied heat flux conditions. This is because of the larger value of average heat flux as shown by dashed lines. This suggests that the wall conduction effect is independent of supplied heat flux. However, one can expect a larger wall conduction at higher heat flux in view of a larger temperature gradient. Nevertheless, the larger temperature gradient on the surface is balance by the large fluid temperature difference between the microchannel inlet and outlet. Therefore, from Eq. 9, it can be concluded that a large supplied heat flux does not necessarily correlate with a large wall conduction.

\section{Discussion}

Table 2 shows the summary of the effect of different geometrical and flow parameters on wall conduction in diverging microchannel. Influence of wall conduction on temperature gradient and heat distribution for each case are presented along with the corresponding wall conduction number $(M)$. Diverging microchannel with small angle of divergence, larger depth and large solid-to-fluid thickness ratio when supplied with low mass flow rate undergoes more wall conduction irrespective of the supplied heat flux. This point gets clear by evaluating the value of conduction number as shown in table. It shows that the percent of standard deviation in heat distribution increases with conduction number 
Table 2: Summary of parametric study showing the effect of various geometrical and flow parameters on wall conduction in diverging microchannel

\begin{tabular}{|c|c|c|c|c|}
\hline \multirow[t]{2}{*}{ Various cases } & & \multicolumn{3}{|c|}{ Diverging microchannel } \\
\hline & & $\begin{array}{c}\text { Tempe- } \\
\text { rature } \\
\text { gradient } \\
\left(\Delta \mathrm{T}_{\mathrm{s}}\right), \\
{ }^{\circ} \mathrm{C} / \mathrm{mm}\end{array}$ & $\begin{array}{c}\text { Standard } \\
\text { deviation } \\
\text { in q' in \% } \\
\text { w.r.t. avg. } \\
\text { value }\end{array}$ & $\begin{array}{l}\text { Conduction } \\
\text { number } \\
(\mathrm{M})\end{array}$ \\
\hline Angle $(\theta),{ }^{\circ}$ & $\begin{array}{l}1 \\
4 \\
8\end{array}$ & $\begin{array}{l}0.60 \\
0.35 \\
0.30\end{array}$ & $\begin{array}{l}26 \\
19 \\
13\end{array}$ & $\begin{array}{l}0.024 \\
0.012 \\
0.010\end{array}$ \\
\hline Depth $(\mathrm{H}), \mu \mathrm{m}$ & $\begin{array}{c}86 \\
120 \\
200\end{array}$ & $\begin{array}{l}0.30 \\
0.20 \\
0.10\end{array}$ & $\begin{array}{l}13 \\
16 \\
21\end{array}$ & $\begin{array}{l}0.010 \\
0.009 \\
0.008\end{array}$ \\
\hline $\begin{array}{l}\text { Solid-to-fluid } \\
\text { thickness ratio }\left(t_{s} / t_{f}\right)\end{array}$ & $\begin{array}{c}1.5 \\
2.32 \\
4.0\end{array}$ & $\begin{array}{l}0.30 \\
0.30 \\
0.30\end{array}$ & $\begin{array}{l}12 \\
13 \\
16\end{array}$ & $\begin{array}{l}0.006 \\
0.010 \\
0.017\end{array}$ \\
\hline $\begin{array}{l}\text { Mass flow rate } \\
(\mathrm{m}), \mathrm{kg} / \mathrm{s}\end{array}$ & $\begin{array}{l}3.3 \times 10^{-5} \\
5.0 \times 10^{-5} \\
8.3 \times 10^{-5}\end{array}$ & $\begin{array}{l}0.45 \\
0.30 \\
0.05\end{array}$ & $\begin{array}{l}21 \\
15 \\
14\end{array}$ & $\begin{array}{l}0.018 \\
0.010 \\
0.002\end{array}$ \\
\hline Supplied heat & 2.4 & 0.08 & 15 & 0.007 \\
\hline flux $\left(q^{\prime \prime}\right), \mathrm{W} / \mathrm{cm}^{2}$ & $\begin{array}{l}4.8 \\
9.6\end{array}$ & $\begin{array}{l}0.30 \\
0.65\end{array}$ & $\begin{array}{l}15 \\
15\end{array}$ & $\begin{array}{l}0.009 \\
0.010\end{array}$ \\
\hline
\end{tabular}

provided $M>0.01$. It is observed that the temperature gradient and thus the variation in heat distribution decrease with the increase in divergence angle. This can be correlated with the conduction number as it is larger for $1^{\circ}$ diverging microchannel $(M=0.024)$ compared to $8^{\circ}$ microchannel $(M=0.010)$. However, for diverging microchannels with varying depth, the percent deviation in heat distribution increases with depth even though the value of $M$ remains just close to 0.01 . Also, in the case of solid-to-fluid thickness ratio, wall conduction number varies from 0.006 to 0.017 even if the temperature gradient remains constant at $0.3{ }^{\circ} \mathrm{C} / \mathrm{mm}$. This suggests the dominance of the solid thickness over the temperature gradient in view of wall conduction effect. With the increase in mass flow rate, the temperature gradient, deviation in heat distribution and conduction number decreases. Finally, the increase in supplied heat flux does not alter the heat distribution This is because, the value of $M \leq 0.01$, although the temperature gradients increase continuously. Detailed study of effect of wall conduction and area variation on temperature gradient in diverging microchannel is presented in Duryodhan et al. (2016).
As mentioned earlier, previous literature focused on analysis of heat flux distribution instead of heat distribution to study the conjugate heat transfer. On the contrary, the present work focuses on heat distribution in order to isolate the effect of area variation from heat flux redistribution. However, to explain the difference between two approaches (i.e. heat distribution versus heat flux distribution), the effect of area variation is included in the analysis and presented in Fig. 8. Figure shows the comparative study of variation of heat (filled symbols) and heat flux (unfilled symbols) in diverging microchannels at various conditions.

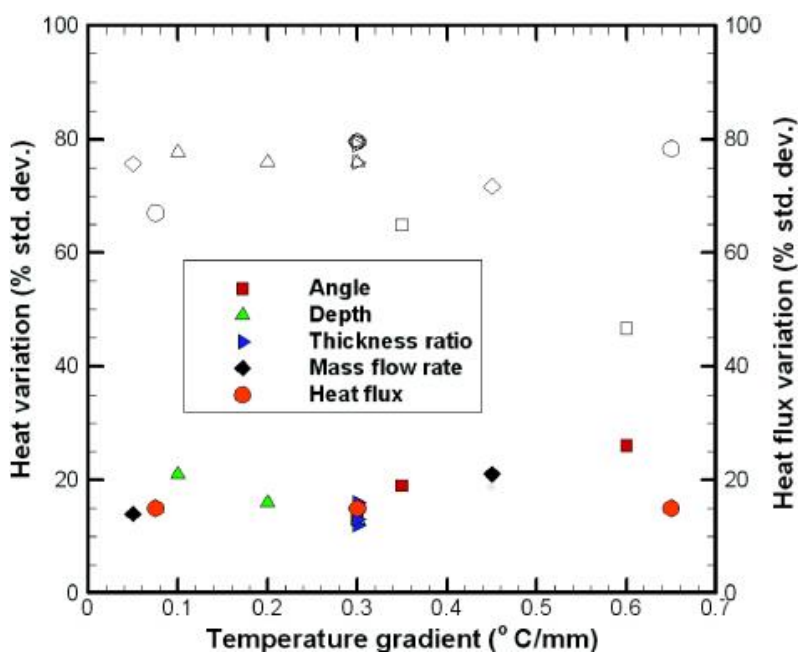

Fig. 8: Variation of heat (filled symbols) and heat flux (unfilled symbols) with temperature gradient in diverging microchannels at various conditions

It can be seen that the values of heat flux deviation (unfilled symbols) are far larger than the values of heat deviation (filled symbols). Therefore, the prediction of effect of wall conduction would mislead if one consider the heat flux variation instead of heat variation. For example for a given temperature gradient of $0.2^{\circ} \mathrm{C} / \mathrm{mm}$, one can get $75 \%$ deviation in heat flux variation instead of $15 \%$ deviation in heat variation. However, in view of low values of wall conduction number $(\mathrm{M}=0.006-0.024)$ shown in Table 2, one can expect the less conduction effect and hence less standard deviation in heat variation for diverging microchannel. Therefore, use of heat variation in the study of conjugate heat transfer of varying cross section microchannel seems to be more appropriate. 


\section{Conclusions}

Effect of wall conduction on redistribution of heat in diverging microchannel has been studied in this paper. Three-dimensional numerical simulations are carried out on various cases with different geometrical (i.e. varying angle: $1-8^{\circ}$, depth: $86-200 \mu \mathrm{m}$ and solid-tofluid thickness ratio: $1.5-4$ ), and flow (i.e. varying mass flow rate: $3.3 \times 10^{-5}-8.3 \times 10^{-5} \mathrm{~kg} / \mathrm{s}$, heat flux: $2.4-9.6$ $\mathrm{W} / \mathrm{cm}^{2}$ ) configurations. Heat distribution along the flow direction is plotted and discussed for all the cases. Results are also analysed in terms of wall conduction number $(M=0.006-0.024)$. Wall conduction in diverging microchannel is observed to be a direct function of depth and solid-to-fluid thickness ratio;

\section{References}

Agrawal A, Duryodhan V S and Singh S G (2012) Pressure drop measurements with boiling in diverging microchannel Frontiers in Heat and Mass Transfer 3013005

Celata G P, Cumo M, Marconi V, McPhail S J and Zummo G (2006) Microtube liquid single-phase heat transfer in laminar flow Int J Heat Mass Transfer 49 3538-3546

Duryodhan V S, Singh A, Singh S G and Agrawal A (2016) A simple and novel way of maintaining constant wall temperature in microdevices Scientific Reports 618230

Duryodhan V S, Singh A, Singh S G and Agrawal A (2015) Convective heat transfer in diverging and converging microchannels Int J Heat Mass Transfer 80 424-438

Fedorov A G and Viskanta R (2000) Three-dimensional conjugate heat transfer in the microchannel heat sink for electronic packaging Int J Heat Mass Trans 43 399-415

Fu B R and Pan C (2010) Simple channel geometry for enhancement of chemical reactions in microchannel Ind Eng Chem Res 49 9413-9422

Hsieh S S, Chen J H and Tsai C F (2013) DNA molecule stretching through thermoelectrophoresis and thermal convection in a heated converging-diverging microchannel Nanoscale Research Letters 8 1-13 whereas it varies inversely with angle and mass flow rate. In addition, the wall conduction is observed to be independent of supplied heat flux.

Present work also justifies the use of heat distribution instead of heat flux distribution in the study of conjugate heat transfer in varying cross sectional microchannel. It is revealed that diverging microchannel leads to relatively small temperature gradients. This work proposes a method for analysing conjugate heat transfer effects in varying cross sectional microchannels. The results presented here are significant to the development of microdevices in which maintaining constant or specified low temperature gradient are utmost important.

Kates B and Ren C L (2006) Study of Joule heating effects on temperature gradient in diverging microchannels for isoelectric focusing applications Electrophoresis 27 19671976

Lee P C and Pan C (2008) Boiling heat transfer and two-phase flow of water in a single shallow microchannel with a uniform or diverging cross section J Micromech Microeng 18025005

Maranzana G, Perry I and Maillet D (2004) Mini- and microchannels: influence of axial conduction in the walls Int $J$ Heat Mass Trans 47 3993-4004

Moharana M K, Agarwal G and Khandekar S (2011) Axial conduction in single-phase simultaneously developing flow in a rectangular mini-channel array Int J Therm Sci $\mathbf{5 0}$ 1001-1012

Morini G L and Yang Y (2013) Guidelines for the determination of single-phase forced convection coefficients in microchannels J Heat transfer 135101004

Xuan X, Xu Bo and Li D (2005) Accelerated particle electrophoretic motion and separation in convergingdiverging microchannels Anal Chem 77 4323-4328

Yong J Q and Teo C J (2014) Mixing and heat transfer enhancement in microchannels containing converging-diverging passages Journal of Heat Transfer 136041704. 